\title{
Low-temperature synthesis of allyl dimethylamine by selective heating under microwave irradiation used for water treatment
}

\author{
Binghui Tian*, Zhaokun Luan, Mingming Li \\ State Key Laboratory of Environmental Aquatic Chemistry, Research Center for Eco-Environmental Sciences, \\ Chinese Academy of Sciences, P. O. Box 2871, Beijing 100085, China
}

Received 25 August 2004; accepted 24 October 2004

\begin{abstract}
Low-temperature synthesis of allyl dimethylamine (ADA) by selective heating under microwave irradiation (MI) used for water treatment is investigated. The effect of MI, ultrasound irradiation (UI) and conventional heating on yield of ADA, reaction time and the flocculation efficiency of polydiallyl dimethylammunion chloride (PDADMAC) prepared form ADA were studied. The results show that by selective heating at low temperature, MI not only increases yield of ADA and reduces reaction time, but also greatly enhances the flocculation efficiency of PDADMAC.

(C) 2004 Elsevier Ltd. All rights reserved.
\end{abstract}

Keywords: Microwave irradiation; Low temperature; Selective heating; Flocculation; Allyl dimethylamine

\section{Introduction}

Microwave irradiation (MI) has gained increasing interest in recent years, and has been used more and more as an activation method for a number of organic synthesis (Berlan, 1995; Chen et al., 2004; Caddick, 1995; Fini and Breccia, 1999). The main benefits of performing reactions under MI are the significant rateenhancement and the higher product yields. However, MI is generally not effective for organic synthesis at low temperature, while most microwave-assisted organic syntheses were carried out at high temperatures by using the thermal action of MI (Dollington et al., 1991; Cherng, 2002). To our knowledge, only few papers on organic syntheses under MI at low temperature have been reported. Bose et al. (1991), Sun et al. (1988) and

\footnotetext{
*Corresponding author. Tel.: + 8601062849150 ; fax: +8601062849198 .

E-mail addresses: tbh_8@163.com (B. Tian), Luanzk@ mail.rcees.ac.cn (Z. Luan).
}

Lewis et al. (1992) reported the athermal action of MI on organic synthesis at low temperature. Huang et al. (1996a b) studied the kinetics theory of MI on chemistry synthesis at different temperatures. The results showed that the acceleration of chemical reaction with MI is caused by not only the dielectric heating, but also the athermal action. MI can cause the variation of activation energy and pre-exponential factor. But these early reports have been discounted as merely thermal effects. Because it is clear that when irradiating organic materials in a microwave, oven the frequency of the radiation $(2.45 \mathrm{GHz})$ does not "activate" specific bonds in a molecule. It has been agreed that microwave heating will not lead to any kinetic differences compared to any other form of heating (Caddick, 1995).

Allyl dimethylamine (ADA) is an intermediate in the reaction process of preparing diallyl dimethylammonium chloride (DADMAC), whose polymers have potential applications in various fields (Wandrey et al., 1999; Mastsumoto, 2001; Ren et al., 2001) (Scheme 1). In reference to the literatures (Wandrey et al., 1999; 
Step I (forming ADA)

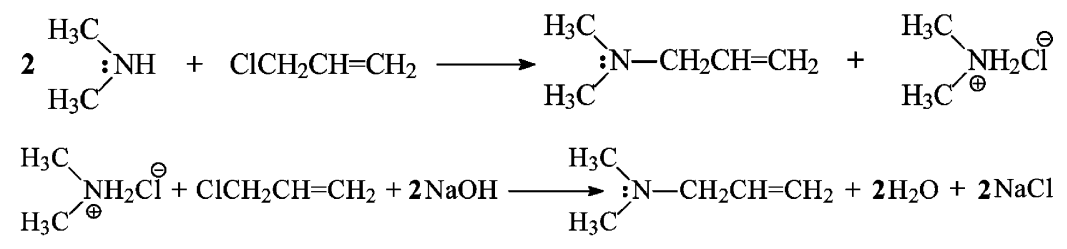

Step II (quaterisation)<smiles>C=CCN(C)CC=CCCl</smiles>

\section{Side reaction}<smiles>C=CC[Cl+]OC(=O)C=CCO</smiles>

Scheme 1. Synthesis of diallyldimethylammonium chloride.

Brain, 1995; Butler and Angelo, 1958; Butler and Bunch, 1949; Negi et al., 1967) as well as our previous works (Zhao et al., 2002; Chang et al., 2000), synthesis of ADA is a key step for producing higher molecular weight polymers of DADMAC (PDADMAC) as a flocculant. In the conventional methods, the yields of ADA at both high temperature and low temperature are too low and reaction time is long so that yield of high-purity DADMAC is lower than $57 \%$ and reaction time is longer than $6 \mathrm{~h}$. This problem seriously inhibits the application of higher molecular weight polymer of DADMAC as a highly efficient flocculant.

In this paper, we wish to report a novel process: low temperature synthesis of ADA under microwave irradiation in order to prepare high molecular weight PDADMAC as a highly efficient flocculant. The work presented is mainly aimed at reducing reaction time and improving the yield of ADA. Though there seems a paradox between microwave irradiation and low temperature, it may be explained as a result of selective heating within the heterogeneous reaction. In order to study the reaction mechanism, the effects of MI, ultrasound irradiation (UI) and the conventional heating on the process were investigated. The flocculation efficiency of high molecular weight PDADMAC prepared by the products from this method was studied. The results showed that this novel reaction procedure is highly efficient and affords higher yield and shorter reaction time. Compared with conventional methods, the results clearly show a significant effect of microwave on a heterogeneous reaction by selective heating at low temperature.

\section{Experimental part}

\subsection{Apparatus}

The self-improved domestic microwave oven, LG Korea, is used. Its irradiation power is from 75 to $750 \mathrm{~W}$. In the modified microwave oven, the reactor is a $50 \mathrm{ml}$ flask placed in a beaker containing $500 \mathrm{ml}$ ice-water (8:2) mixture for controlling the reaction temperature. This flash is attached to a four-way tube connected with a reflux condenser, stirring apparatus and a filling tube. This system allows for different adding methods of $\mathrm{NaOH}$ (the addition of the $\mathrm{NaOH}$ solution or the solid $\mathrm{NaOH}$ ) under microwave irradiation at low temperature.

The sonochemical experiments and the tradition synthesis were carried out in a Branson S3200 $(50 \mathrm{kHz}, 150 \mathrm{~W}$, USA) ultrasonic cleaning bath and in magnetic mixer (YY 90-3, China) under ice water bath, respectively.

\subsection{Materials}

Allyl chloride, dimethylamine and sodium hydroxide are chemically pure. All the reagents are domestic products and are used without further purification. Distilled water is used for the preparation of all solution.

\subsection{General procedures of synthesis of $A D A$ by $M I, U I$} and conventional heating

To investigate the effect of MI, UI and the conventional heating on reaction of forming $\mathrm{ADA}$, conversion 
of dimethylamine determined by a fashion in which thymophthalein was used as an indicator (Butler and Angelo, 1958; Hunter, 1979; Chang et al., 2000). After the $33 \%$ aqueous solution of dimethylamine $(0.1 \mathrm{~mol})$ was charged into the flask from the filling tube and cooled to $5^{\circ} \mathrm{C}$ under ice-water bath and stirring. Then allyl chloride $(0.1 \mathrm{~mol})$ was added and cooled. Finally, $\frac{1}{10}$ of $40 \%$ aqueous solution of sodium hydroxide or solid sodium hydroxide $(0.1 \mathrm{~mol})$ was added. The microwave oven (or ultrasound reactor) was started up with the power of $150 \mathrm{~W}$ under stirring until the blue color disappeared. The reaction time was recorded in order to draw the curve of the conversion of dimethylamine. Then another $\frac{1}{10} \mathrm{NaOH}$ solution/solid $\mathrm{NaOH}$ was added and the reaction time was recorded again when the blue color disappeared. The process was repeatedly carried out until the blue color did not disappear after adding $\mathrm{NaOH}$ for long time.

Yields of tertiary amine are calculated from highpurity DADMAC yield. The concentration of produced DADMAC aqueous solution was measured by the precipitation titration using sodium tetrephenylboron.

\subsection{The flocculation test}

For the flocculation tests, a total of $1 \mathrm{~L}$ of water was transferred to a $1 \mathrm{~L}$ beaker. Under rapid stirring conditions, $15 \mathrm{ml}$ of the stock kaolin suspension (100 g/ L) was added by using a micropipet, giving a clay concentration of $1500 \mathrm{mg} / \mathrm{L}$. The flocculation experiments were conducted at room temperature $\left(20-23^{\circ} \mathrm{C}\right)$. Prior to the addition of flocculants, the target $\mathrm{pH}$ was adjusted by adding a predetermined amount of $\mathrm{NaOH}$ or $\mathrm{HCl}$ into the kaolin suspension, with rapid stirring. The flocculant was added using a micropipet. After being dosed, $1 \mathrm{~min}$ of rapid mixing at $300 \mathrm{rpm}$ was applied, followed by $10 \mathrm{~min}$ of slow stirring at $40 \mathrm{rpm}$. The flocs were allowed to settle for $30 \mathrm{~min}$, and the residual turbidity (RT) was measured using a $\mathrm{HACH}$ 2100N Tubidimeter (Hach, Loveland, Co).

Throughout the mixing and coagulation periods, the suspension was continuously sampled by peristaltic pump and monitored by a photometric dispersion analyzer (PDA 2000; Rank Brothers Ltd.) to obtain a flocculation index (FI).

\section{Results and discussion}

\subsection{Synthesis of ADA by conventional heating at different temperature}

Fig. 1 shows that variations of dimethylamine conversion with reaction time by conventional method at different temperatures. Results in Fig. 1 indicate that the conversion of dimethylamine increases obviously

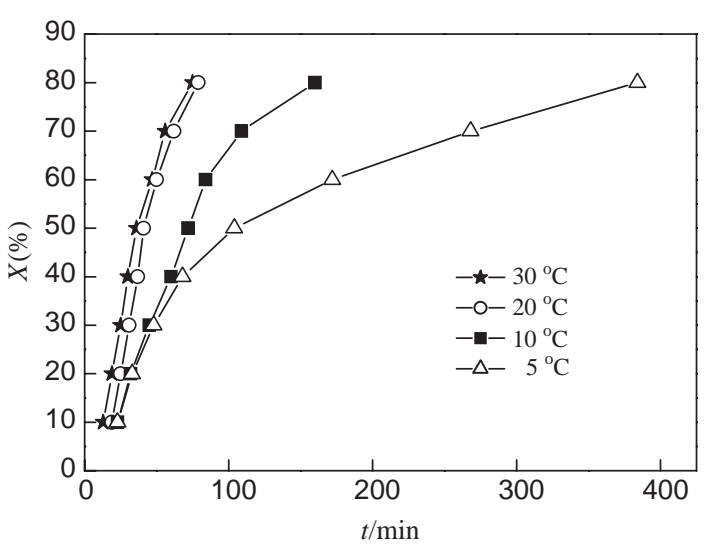

Fig. 1. Variation of dimethyl amine conversion with reaction time using conventional method.

with increasing the reaction temperature. However, from Table 1, it is found that the yield of ADA is not improved with an increase of the reaction temperature, especially all these yields at different temperatures are lower than $60 \%$, though the reaction time at the optimum point can be reduced with increasing reaction temperature. The cause is that with increasing reaction temperature by conditional heating, reaction rates of side reaction and the quaterization reaction are more obviously accelerated than reaction rate of forming ADA (Boothe, 1969; Hunter, 1979; Zhao et al., 2002).

\subsection{Synthesis of ADA by MI, UI and conventional heating at low temperature}

Table 2 illustrates different yields of ADA by MI, UI and conventional heating at low temperature. It is found that MI, UI or the addition of solid $\mathrm{NaOH}$ has a significant effect upon yields of ADA at low temperature. In particular, under the condition of MI and using the addition of solid $\mathrm{NaOH}$, the optimum yield of ADA is improved to $71 \%$ and reaction time is only $7 \mathrm{~min}$.

In order to better understand the reaction mechanism of forming ADA by MI, UI and conditional heating at low temperature, variations of dimethylamine conversion with reaction time by MI, UI and conventional heating at low temperature are shown in Fig. 2. The figure shows that MI has a significant effect upon the conversion of dimethylamine, especially in the region where conversion of dimethylamine is higher than $40 \%$. It is highly probable that the reaction system consists of two phases: water phase and oily phase. The reaction of forming $\mathrm{ADA}$ is carried out at the interface of two phases, while the reaction of producing DADMAC is carried out in the oily phase. MI heating can rapidly heat water phase whose dielectric constant is large, whereas oily phase whose dielectric constant is small do not couple and therefore is not heated with MI although 
Table 1

Yields of ADA by conventional method

\begin{tabular}{|c|c|c|c|c|c|}
\hline \multirow[t]{2}{*}{ Different temperatures } & \multicolumn{5}{|c|}{ Yields of tertiary amine $(\%)$} \\
\hline & $30 \mathrm{~min}$ & $60 \mathrm{~min}$ & $120 \mathrm{~min}$ & $240 \mathrm{~min}$ & $480 \mathrm{~min}$ \\
\hline $5^{\circ} \mathrm{C}$ & 10.7 & 18.9 & 35.2 & 57.8 & 57.5 \\
\hline $10^{\circ} \mathrm{C}$ & 17.8 & 43.6 & 58.9 & 59.2 & 58.5 \\
\hline $20^{\circ} \mathrm{C}$ & 40.6 & 58.2 & 57.6 & 57.1 & 56.9 \\
\hline $30^{\circ} \mathrm{C}$ & 45.3 & 60.2 & 58.5 & 57.8 & 57.5 \\
\hline
\end{tabular}

Table 2

Yields of ADA by MI, UI and conventional method at low temperature $\left(5^{\circ} \mathrm{C}\right)$

\begin{tabular}{|c|c|c|c|c|}
\hline \multirow[t]{2}{*}{ Different methods } & \multicolumn{4}{|c|}{ Yields of tertiary amine $(\%)$} \\
\hline & $3 \mathrm{~min}$ & $7 \mathrm{~min}$ & $11 \mathrm{~min}$ & $15 \mathrm{~min}$ \\
\hline Adding $40 \% \mathrm{NaOH}$ solution & Trace & 1.8 & 3.6 & 5.1 \\
\hline UI, adding $40 \% \mathrm{NaOH}$ solution & 1.8 & 3.6 & 5.7 & 8.9 \\
\hline MI, adding $40 \% \mathrm{NaOH}$ solution & 2.1 & 4.4 & 6.3 & 9.8 \\
\hline Adding solid $\mathrm{NaOH}$ & 16.3 & 28.2 & 41.5 & 46.5 \\
\hline UI, adding solid $\mathrm{NaOH}$ & 18.2 & 28.9 & 42.3 & 47.8 \\
\hline MI, adding solid $\mathrm{NaOH}$ & 37.0 & 71.0 & 70.2 & 70.5 \\
\hline
\end{tabular}

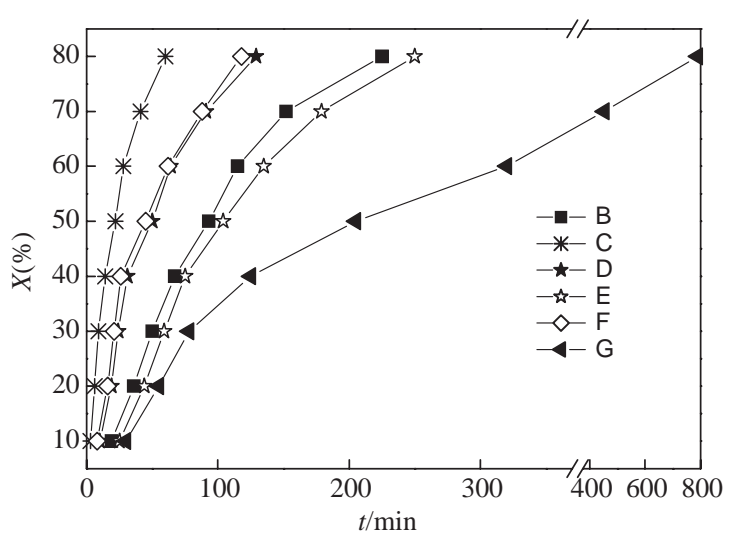

Fig. 2. Variations of dimethyl amine conversion with reaction time by MI, UI and conventional method at low temperature $\left(5{ }^{\circ}\right.$ C). (B): $\mathrm{MI}, 40 \% \mathrm{NaOH}$ solution; (C): $\mathrm{MI}$, solid $\mathrm{NaOH}$; (D): solid $\mathrm{NaOH}$; (E): UI, 40\% $\mathrm{NaOH}$ solution; (F): UI, solid $\mathrm{NaOH} ;(\mathrm{G}): 40 \% \mathrm{NaOH}$ solution.

it is of course heated by heat transport from water phase. At low temperature, MI can accelerate reaction rates of forming ADA by selective heating and accelerating mass transport in the water phase. At the same time, reaction rates of producing byproducts and DADMAC can be observably inhibited at low temperatures of the system and the oily phase. Therefore, reaction rate, yield and purity of ADA are remarkably increased. The most interesting phenomenon can be found that conversion of dimethylamine and the yield of forming ADA are dramatically increased under MI heating and by using the addition method of solid $\mathrm{NaOH}$. All these results seem to suggest that at low temperature, dissolution heating generated from water phase, as MI heating, also can selectively heat water phase to accelerate reaction rate of forming ADA at the phase interface and mass transport of dimethylamine in water phase. In conclusion, the selective heating at low temperature is significantly enhanced by MI heating and using addition of solid $\mathrm{NaOH}$ together.

Fig. 2 also shows that in the present experiments, UI has also significant effect on the conversions of dimethylamine using the addition of $40 \% \mathrm{NaOH}$ solution, as well as on the yield of forming ADA as shown in Table 2. The reason maybe is that UI can accelerate the reaction rate of the heterogeneous reaction by "hot theory" action and accelerating mass transport (Mason, 1994; Birkin and Susana, 1996). But UI has little effect on conversions of dimethylamine using the addition of solid solution. This phenomenon probably suggests that UI does not selectively affect water phase at low temperature.

\subsection{The flocculation test}

Homopolymer of high intrinsic viscosity $(\eta=2.7)$ can be prepared from ADA by the two-step method. This value is far higher than that of homopolymer prepared by conventional method, whose intrinsic viscosity is 


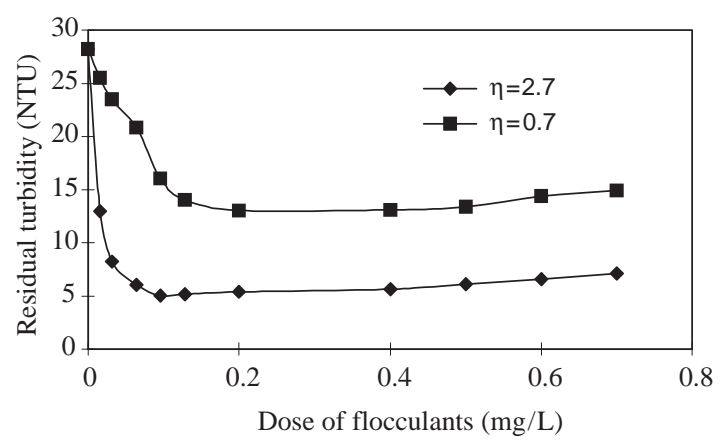

Fig. 3. Effect of different molecular weight PDADMAC on the flocculation of kaolin suspensions.

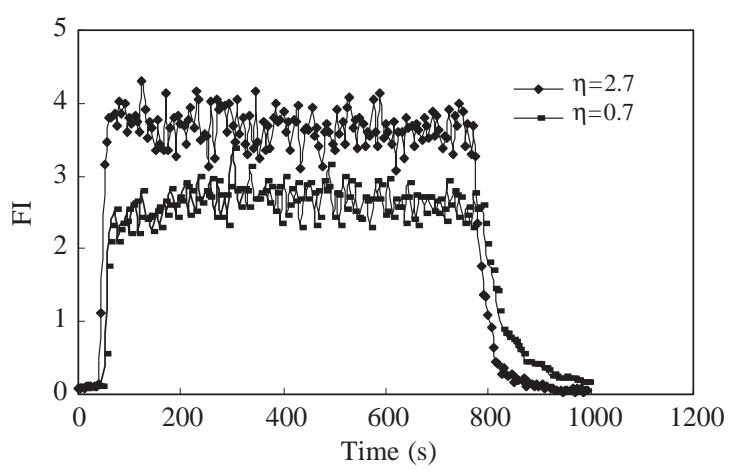

Fig. 4. Effect of different molecular weight PDADMAC on flocculation index at the optimum point for the systems.

about 1.0. Using the above homopolymers as flocculants, the flocculation test was carried out by the jar test. The results are shown in Figs. 3 and 4. Fig. 3 shows that both the optimum dose and the optimum residual turbidity by using PDADMAC of $\eta=2.7$ as flocculant was smaller than those by using PDADMAC of $\eta=1.0$. Fig. 4 shows that using PDADMAC of $\eta=2.7$ as flocculant, the floc size is larger, the floc is more stable and the settling rate is higher. These phenomena indicate that the high intrinsic viscosity $(\eta=2.7)$ PDADMAC prepared from ADA is advantageous in flocculation. It can be suggested by the "bridging action" of flocculants: higher the molecule weight, stronger the "bridging action". All above results are in favor of low temperature synthesis of ADA under MI.

\section{Conclusion}

Low-temperature synthesis of allyl dimethylamine by selective heating under microwave irradiation used for water treatment is described. The effect of microwave irradiation, ultrasound irradiation and conventional heating on the reaction at low temperature was investigated. Compared with conventional methods, the results show that MI has a significant effect on a heterogeneous reaction at low temperature by selective heating. Moreover, the selective heating at low temperature is significantly enhanced by MI heating and addition of solid $\mathrm{NaOH}$ together. The results also show that yield of forming ADA is improved from $60 \%$ to $71 \%$ and reaction time is reduced from $2-6 \mathrm{~h}$ to $7 \mathrm{~min}$ by selective heating under microwave irradiation and using the addition of solid $\mathrm{NaOH}$. At particular, higher molecular weight polydiallyldimethylammunion chloride prepared from ADA has higher flocculation efficiency.

\section{Acknowledgements}

We are grateful for the financial support by the National 10th Five-year Science and Technology Project of China (No. 2002BA806b04-01B) and the Natural Sciences Foundation of China (No. 50308028, 5030806).

\section{References}

Berlan, J., 1995. Microwaves in chemistry: another way of heating reaction mixing. Radiat. Phys. Chem. 45, 581-589.

Birkin, P.R., Susana, S.M., 1996. A study of the effect of ultrasound on mass transport to a microelectrode. J. Electroanal. Chem. 416 (1-2), 127-138.

Boothe, J. E., 1969. Synthesis of dimethyl diallyl ammonium chloride.[P] USA 3,461,163.

Bose, A.K., Manhas, M.S., Ghosh, M., 1991. Microwaveinduced organic reaction enhancement chemistry: 2. Simplified techniques. J. Org. Chem. 56, 6968-6970.

Brain, A.B., 1995. Soluble polymers in water purification. Prog. Polym. Sci. 20, 987-1041.

Butler, G.B., Angelo, R.J., 1958. Preparation and polymerization of unsaturated quaternary ammonium compounds: VIII. A proposed alternating intramolecular-intermolecular chain propagation. J. Am. Chem. Soc. 73, 3128-3131.

Butler, G.B., Bunch, R.L., 1949. Preparation and polymerization of unsaturated quaternary ammonium compounds. J. Am. Chem. Soc. 71, 3120-3122.

Caddick, S., 1995. Microwave assisted organic reactions. Tetrahedron 51, 10404-10432.

Chang, Q., Chen, Y., Tian, B.H., 2000. Study on synthesis and flocculation efficiency of polydimethyldiallylammonium chloride. J. Environ. Sci. 20, 168-172.

Chen, G.J., Zhu, X.L., Cheng, Z.P., 2004. Controlled/ "living"radical polymerization of methyl methacrylate using AIBN as the initiator under microwave irradiation. Radiat. Phys. Chem. 69, 129-135.

Cherng, Y.J., 2002. Synthesis of substituted pyridines by the reactions halopyridines with sulfer, oxygen and carbon nucleophiles under focused microwave irradiation. Tetrahedron 58, 4931-4935. 
Dollington, S.D., Bond, G., Moyes, R.B., 1991. The influence of microwaves on the rate of reaction of propanal with ethanoic acid. J. Org. Chem. 56, 1313-1317.

Fini, A., Breccia, A., 1999. Chemistry by microwaves. Pure Appl. Chem. 71, 573-579.

Huang, K.M., Liu, Y.Q., Tang, J.X., 1996a. A study of athermal action of electromagnetic waves on chemical reaction. Chem. J. Chin. Univ. 17, 764-768.

Huang, J.T., Sun, J.W., Cao, A.L., 1996b. Synthesis and polymerization of diallylaromatic amines as supernucleophilic reagents. Polymer 37, 837-841.

Hunter, W.E., 1979. Preparation of diallyl dimethyl ammonium chloride and polydiallyl dimethyl ammonium chloride.[P]. USA 4, 151, 202.

Lewis, D.A., Summers, J.S., Ward, T.C., 1992. Accelerated imidization reactions using microwave radiation. J. Polym. Sci. A 30, 1647-1653.

Mason, T.J., 1994. Free radicals and ultrasound in chemistry and medicine. Ultrason. Sonochem. 1, 131-132.
Mastsumoto, A., 2001. Polymerization of multiallyl monomers. Prog. Polym. Sci. 26, 189-257.

Negi, Y.J., Harada, S., Ishizuka, O., 1967. Preparation and cyclopolymerization of diallylamine derivatives. J. Polym. Sci.: Part A-1 5, 1951-1965.

Ren, J., Ha, H.F., 2001. Study on interpenetrating polymer network hydrogel of diallydimethylammonium chloride with kappa-carrageenan by UV irradiation. Europ. Polym. J. 37, 2413-2417.

Sun, W.C., Guy, P.M., Jahngen, J.H., 1988. Microwaveinduced hydrolysis of phospho anhydride bonds in nucleotide triphosphates. J. Org. Chem. 53, 4414- 4416.

Wandrey, C., Hernández-barajas, J., Hunkeler, D., 1999. Diallyldimethylammonium chloride and its polymer. Advs. Polym. Sci. 145, 82-123.

Zhao, H.Z., Luan, Z.K., Gao, B.Y., 2002. Synthesis and flocculation properties of poly(diallyldimethyl ammonium chloride-vinyl trimethoxysilane. J. App. Polym. Sci. 84, 335-342. 